\title{
FutureJournal
}

\section{Melhoria de Desempenho em Segmentos altamente Competitivos: a Gestão Baseada em Valor (GBV) na Indústria Têxtil Brasileira}

\author{
Paschoal Tadeu Russo \\ Professor da Fundação Instituto de Pesquisas Contábeis, Atuariais e Financeiras, FACULDADE \\ FIPECAFI, Brasil. \\ ptrusso@terra.com.br
}

\section{Claudio Parisi}

Professor da Fundação Escola de Comércio Álvares Penteado, FECAP, Brasil. claudio.parisi@uol.com.br

\section{RESUMO}

Neste relato técnico, o objetivo é apresentar os benefícios gerados pela utilização da Gestão Baseada em Valor (GBV) para a gestão do desempenho econômico de indústrias, de forma geral, mais especificamente no setor têxtil de não vestuário brasileiro, um setor altamente competitivo, como uma forma de maximizar o retorno sobre o capital investido na empresa. A intervenção observada ocorreu no período de final de 2012 a 2015 quando a empresa estudada, com mais de 40 anos de existência e de gestão familiar, mudou sua estrutura organizacional, passando de funcional para descentralizada por unidades de negócio. Tal mudança causou necessidades de alterações do processo de avaliação do desempenho, o que permitiu a implantação da GBV. Essa implantação possibilitou a melhoria do processo de gestão e dos sistemas de informação, contribuindo, consequentemente, com a melhoria do desempenho dos gestores e da organização. Entende-se que a GBV se apresenta como uma ferramenta que contribui para os processos de gestão que levam à criação de valor para as organizações e oferece elementos de mensuração do lucro econômico como uma medida do lucro residual relativo aos custos de capital da organização.

PALAVRAS-CHAVE: Gestão Baseada e Valor. Modelo de Gestão. Lucro Econômico. EVA. 


\section{FutureJournal}

\section{Performance Improvement in Highly Competitive Segments: Value-}

Based Management (VBM) in the Brazilian Textile Industry

\section{ABSTRACT}

This technical report aims to present the benefits generated by the use of Value Based Management (VBM) to the economic performance management on industries in general, more specifically in the Brazilian non-clothing textile sector a highly competitive sector, as a way to maximize the return on capital invested in the company. The observed intervention occurred in late 2012 period to 2015 when the company studied, with over 40 years of existence and family management, changed its organizational structure, from functional to decentralized by business units. This change caused changes in the performance assessment process, which allowed the implementation of VBM. This deployment has enabled the improvement of management processes, improving information systems and thus contributed to the improved performance of management and the organizations. VBM is presented as a tool that contributes to the management processes that lead to creating value for organizations and provides measurement of economic profit elements as a measure of the residual profit relative to the organization's capital costs.

KEY-WORDS: Value-based management. Management model. Economic profit. EVA 


\section{INTRODUÇÃo}

O setor industrial vem sofrendo reduções sucessivas nas últimas décadas. Parte pela implantação de um conjunto de políticas tributárias que deixaram de privilegiar a atividade industrial e parte pela falta de políticas de longo prazo. Dentre os diversos segmentos da indústria brasileira, o da indústria têxtil, além de lidar com as questões nacionais internas, tem se deparado com uma forte concorrência internacional advinda principalmente da China e da Índia.

Esse quadro tem levado muitas indústrias têxteis que ainda sobreviveram a um processo de desmantelamento de seus parques industriais e têm se tornado grandes importadoras, a transferirem suas atividades industriais básicas para atividades secundárias, como as de confecções. Lamentavelmente outro grupo de empresas não conseguiu sobreviver. Dentro desse contexto, saber escolher o que e onde produzir, como gerir os estoques, o que vender, e como conceder prazos de pagamentos aos clientes tornou-se ainda mais fundamental.

Em contextos de alta competitividade e de crise (como o que é caracterizado neste momento no Brasil) é comum, como parte do esforço para a concretização das vendas, que as organizações reduzam as margens e concedam mais prazos de recebimento. Entretanto, isso pode ter um alto custo para a continuidade da organização. Como consequência, não raro os lucros auferidos por essas organizações não são suficientes para cobrir os custos dos capitais demandados pelas atividades operacionais. Quando isso acontece, a organização destrói valor econômico e desvaloriza-se. Pode-se dizer que a organização vai perdendo valor dia a dia. Dependendo das métricas utilizadas pela organização na gestão do lucro e do valor, isso não é percebido facilmente pelo gestor nem pelos acionistas, e quando ele se dá conta, os níveis de endividamento podem ter se tornado críticos.

É importante que, mesmo em meio à turbulência gerada nos contextos acima descritos, a organização disponha de indicadores centrais de desempenho que identifiquem se as tomadas de decisões diárias estão sendo efetivas para a geração de valor e para a continuidade dos negócios. Entretanto, são tantos indicadores disponíveis para o processo de gestão, 
que, mesmo se contando com sistemas integrados de informação e com profissionais capacitados, as decisões podem não ser as mais adequadas.

É nesse contexto que a implantação e o uso da Gestão Baseada em Valor (GBV) como base de mensuração e de processo de gestão podem auxiliar na geração de valor e a na perpetuidade das organizações. A compreensão do uso dessa metodologia como base de mensuração, e como suporte à tomada de decisão, pode trazer ganhos significativos para as organizações deste e de outros setores industriais (e não industriais) brasileiros.

Dessa forma, o objetivo deste relato é apresentar os benefícios gerados pela utilização da GBV para a gestão do desempenho econômico de indústrias, de forma geral, mais especificamente no setor têxtil brasileiro, um setor altamente competitivo, como forma de maximizar o retorno sobre o capital investido na empresa. Como contribuição para a prática, levam-se em conta os resultados da intervenção que aconteceu no final de 2012 e começo de 2013 em uma empresa do setor têxtil, com gestão familiar, e com mais de 40 anos de atividade. Pretende-se contribuir por meio deste relato como orientação e inspiração para outras empresas utilizarem a GBV.

\section{REFERENCIAL TEÓRICO}

\subsection{VISÃO GERAL SOBRE A GESTÃO BASEADA EM VALOR}

A Gestão Baseada no Valor - GBV (Value Based Management - VBM) é um modelo de gestão. Trata-se de "um processo sistêmico que orienta toda a tomada de decisão de uma organização no intuito da criação do valor" (Cabello, Parisi \& Oliveira, 2007, p. 2). Seu objetivo é a maximização da riqueza dos proprietários de capital com uma visão essencialmente de longo prazo, visando à continuidade e à capacidade de competição da empresa no longo prazo (Assaf, 1999).

Como medida da criação de desempenho, a GBV vale-se do conceito de lucro econômico, um termo utilizado para descrever a medida que o lucro gerado por uma organização excede ou falta ao custo demandado pelo capital 
investido. Essa medida é bastante antiga tendo sido utilizada por diversos economistas dos séculos XIX e XX (Assaf, 1999).

Como um processo sistêmico, a GBV deve permear todos os níveis hierárquicos da organização, com o intuito de que todas as ações sejam orientadas para a geração de valor, levando em conta os direcionadores de valor (value drivers), ou seja, os fatores capazes de interferir no valor da empresa. Esse processo requer que os gestores tenham uma mudança comportamental e passem a atuar estritamente na busca desse objetivo.

Os direcionadores de valor são medidas proativas sobre as quais as empresas podem atuar para antecipar resultados, com o objetivo de criar valor para os acionistas. Eles são parâmetros básicos de avaliação e podem ser de dois tipos: financeiros e não financeiros. Os financeiros são de caráter histórico e avaliam o desempenho depois de o fato ter ocorrido, por isso são chamados indicadores de ocorrência (lagging indicators). Os não financeiros, também chamados de indicadores de tendência (leading indicators), são importantes, pois têm a capacidade de prever a criação de valor e, dessa forma, auxiliam as empresas na busca pelo aumento do valor. De modo geral, os direcionadores não financeiros estão associados à eficiência operacional da empresa e são necessários para complementar as informações financeiras, contudo, são de difícil mensuração (Guimarães Jr., 2009).)

De acordo com o que é identificado na literatura e na prática das organizações, a GBV impacta direta e indiretamente diversas práticas de gestão empresarial, assim, sua influência vai, ao longo do tempo, desde a estruturação do modelo de negócio, o planejamento empresarial (do estratégico ao operacional) até a estrutura de indicadores, que possibilita a identificação dos resultados obtidos. Segundo Ehrbar (1999), a GBV deve ser o único instrumento de gestão; porém, na prática, observa-se que a utilização do planejamento estratégico, do orçamento empresarial (budget), do BSC como integrador entre o planejamento estratégico não suprimem a existência da GBV. Ao contrário, todos os instrumentos citados podem valer-se dela e com isso potencializar os resultados obtidos com seu uso por meio da visão de geração de valor que é obtida (Dória, Camargo Filho \& Bosqueti, 2005; Parisi, 2011).

Desse modo, a prática de GBV mobiliza e depende da participação de toda a organização; sendo assim, para intensificar a congruência entre os 
objetivos dos gestores e os da organização, é interessante que os conceitos que estruturam a base da meritocracia desses profissionais sejam influenciados pelos direcionadores de valor dos quais a GBV se vale. De outro lado, é necessário ocorrerem a conscientização e o envolvimento de todos os colaboradores da organização. Para tanto, sugere-se que seja realizado um processo contínuo de capacitação de todos os envolvidos nos processos de tomada de decisão que geram valor, sobretudo na alta cúpula, na qual se encontra a maior relevância desse entendimento e desse comprometimento.

No processo de implantação da GBV, devem ser levadas em conta a estrutura organizacional e a de produtos, possibilitando, assim, que cada unidade de negócio, linha de produto, atue na identificação das possibilidades que maximizem os resultados, com ações que serão tomadas por meio dos direcionadores de valor.

Identificaram-se pesquisas que se propõem a analisar a implementação da GBV em setores específicos de atividades econômicas, entretanto a maior parte delas já tem mais de dez anos de publicação. Não se observaram novos trabalhos recentes apesar da relevância desse tema para a gestão e principalmente para o momento econômico pelo qual passa o Brasil nesse momento (Cunha \& Frezatti, 2004; Assaf Neto, Araújo \& Fregonesi, 2006; Max \& Soares, 2008; Bonacim \& Araujo, 2009).

\subsection{ECONOMIC VALUE ADDED (EVA) - MEDIDA DE DESEMPENHO}

Uma das formas pelas quais se realiza a mensuração do valor econômico adcionado é a metodologia EVA, que se baseia no conceito de lucro econômico (lucro residual). Desenvolvida nos anos de 1980 pela consultoria Stern Stewart \& Co., ela é uma marca registrada (EVA®) (Castro Junior \& Yoshinaga; 2011).

O EVA é obtido pela subtração dos custos de capital do lucro operacional líquido após a tributação (NOPAT - Net Operting Tax After Tax). Expresso em termos de fórmula, é assim descrito:

$$
E V A=\text { NOPAT }- \text { Custo de Capital }
$$


O custo de capital, por sua vez, é calculado como o produto entre a taxa de custo médio ponderado de capitais da empresa (conhecido como WACC - weighted average cost of capital) e o montante de capital operacional líquido investido (ativos permanentes operacionais, estoques, duplicatas a receber, menos fornecedores a pagar, entre outros).

O custo do capital próprio é definido com base no custo de oportunidade dos investidores para igual risco. O custo do capital de terceiros é aquele pago para as fontes externas de capital já excluindo o benefício fiscal advindo da dedução da tributação dos juros sobre o lucro. Expresso em termos de fórmula, é assim descrito:

\section{Custo de Capital $(\$)=$ WACC $\times$ Capital Operacional Líquido $(\$)$}

O EVA comunica com clareza que o investimento que vale a pena é aquele que gera lucros superiores aos custos de capital, ou seja, evidencia o custo de capital, levando os gestores a promoverem ações que maximizem os lucros e otimizem o uso dos ativos.

\section{METODOLOGIA}

A metodologia de pesquisa usada foi a pesquisa-ação, assim definida por Elliot (citado por Trip, 2005, p. 463): "O estudo de uma situação social com vistas a melhorar a qualidade da ação dentro dela". Dentro desse enfoque, de acordo com Trip (2005), a pesquisa-ação pode ter várias abragências. Nesta pesquisa pretende-se adotar as seguintes: a) pesquisaação-técnica: quando ela visa auxiliar o processo de implementação de uma nova técnica, ou melhorar a existente com base em um roteiro rígido preestabelecido; b) pesquisa-ação-prática: também voltada à implementação de uma técnica, mas, desta vez, o pesquisador escolhe o que implementará. A elaboração do texto deste relato seguiu ainda as recomendações de Biancolino, Kniess, Maccari e Rabechini Jr. (2012).

Visando ao uso adequado da metodologia proposta, foi inicialmente realizado um diagnóstico sobre as dimensões que se pretendia alcançar com a implantação da GBV na organização estudada. Para tanto, foi realizado um planejamento de atividades; em seguida, deu-se início propriamente à 
intervenção; depois foram descritas as observações sobre os resultados obtidos por meio da intervenção; por fim foram analisados, à luz da teoria apresentada, os pontos positivos e negativos identificados.

Os pesquisadores envolvidos neste relato interagiram com a organização estudada enquanto assumiam papéis de consultores externos contratados para a realização da referida intervenção. Foram estabelecidos protocolos de conduta ética que impedem a declaração do nome da empresa. Dessa forma os dados e as informações são aqui descaracterizados para assegurar o direito de confidencialidade da organização estudada.

Essa intervenção foi escolhida pelos pesquisadores para servir de base para este relato como uma forma de evidenciar que, mesmo em organizações que estejam em contextos altamente competitivos e sem grandes estruturas de infomação, a GBV se mostra viável em função de ser um conceito simples, de fácil implantação, que, entretanto, promove benefícios significativos para as organizações que dela se valem.

\section{RESULTADOS OBTIDOS E ANÁLISE}

No final de 2012 e começo de 2013, na empresa estudada, que de agora em diante será chamada de Indústria Têxtil, seu principal gestor, ao qual chamaremos de Presidente, promoveu uma mudança em sua estrutura organizacional, que na origem era puramente funcional, para uma estrutura baseada em unidades de negócios (UNs). Ele acreditava que com isso podería obter um melhor desempenho de seus gestores (aos quais chamaremos de gestores de unidades de negócio), que ficariam mais focados nos mercados e produtos específicos de suas UNs.

Já no início de 2013, foi possível perceber a sensível mudança no volume de vendas de cada uma das UNs e na evolução positiva dos negócios. Entretanto, alguns problemas e conflitos começaram a surgir como decorrência de diferenças percebidas por cada uma das UNs, a saber: políticas comerciais, de investimentos, de utilização de ativos operacionais (edificações, máquinas, estoques, duplicatas a receber, etc.), critério de avaliação de desempenho das UNs e dos gestores das UNs.

A empresa dispunha de uma área de contabilidade internalizada com uma vasta equipe, com um diretor, contadores, analistas e assistentes, 
dentre os quais alguns estavam na organização há mais de 30 anos. Contava ainda com um software de gestão integrada da TOTVS, entretanto as informações disponibilizadas eram usadas somente para fins de apuração fiscal.

Naquela ocasião, por iniciativa do Presidente, nascia uma área de Controladoria, para a qual fora escolhido um controller, que já atuava na empresa há dez anos, não era contador nem conhecia contabilidade, entretanto possuía uma notável capacidade analítica e conhecia profundamente os negócios da empresa.

O controller, à luz da demanda do Presidente, passou a analisar as mudanças decorrentes da alteração da estrutura organizacional, bem como os pontos positivos e os problemas percebidos. Naquela ocasião, tentou promover ações que resolvessem os problemas identificados com os recursos internos da organização, o que não gerou os benefícios esperados. A partir de então, identificou uma empresa de consultoria, a qual será chamada de Consultoria, que se valia de fundamentos contábeis e de gestão econômicofinanceira, à qual foi solicitado um diagnóstico em face dos elementos anteriormente apresentados.

A Consultoria teve dois objetivos em seu diagnóstico. No primeiro, além de confirmar os pontos positivos que estavam ocorrendo, notadamente o aumento das vendas e melhor foco nos negócios, observou os diversos conflitos decorrentes dos critérios de mensuração usados, e sua associação com as políticas de remuneração variáveis utilizadas então, bem como as falhas ou faltas de diversas políticas. O segundo, como consequência do diagnóstico, foi a proposição da metodologia de Gestão Baseada em Valor (GBV) e a utilização da métrica do lucro econômico como medida do desempenho das UNs e da organização como um todo.

O processo de implantação da GBV se deu por fases. A primeira fase visou operacionalizar a GBV com informações obtidas diretamente da contabilidade. Como a classificação das informações na contabilidade não estava alinhada ao conceito de divionalização, foram necessários ajustes. Para tanto, com a finalidade de promover uma rápida adequação dos dados, foram realizados ajustes por meio de planilhas de Excel, fora do ambiente da contabilidade. Entre os ajustes realizados, destacam-se os necessários para a apuração da margem bruta por UN, e margem operacional por UN. Em 
ambos os casos, foram considerados somente os custos e as despesas que podiam ser associados diretamente às UNs. Não foram utilizados rateios, tal decisão baseia-se no princípio da controlabilidade, ou seja, apura-se o resultado que está diretamente associado à capacidade de gestão do gestor da UN, evidenciando a geração de valor. Rateios criam problemas para os gestores, pois corroem os resultados gerados pelas UNs e estão fora do seu alcance. Ainda na primeira fase, foram identificados os ativos operacionais líquidos de cada uma das Uns, que representam os capitais efetivamente disponibilizados para cada uma delas. Cabe ressaltar que todos os ativos, as despesas e os custos que não puderam ser associados diretamente a cada uma das UNs foram associados ao que foi denominado de Unidade Corporativa, o equivalente a uma UN, porém que é responsável pelas funções corporativas.

A segunda fase visou atribuir o custo de oportunidade para os capitais operacionais líquidos disponibilizados. Para tanto foi utilizada a metodologia do CAPM (Capital Asset Price Model), como base da precificação do custo do capital próprio. Dada a dificuldade de obtenção dos indicadores necessários à estruturação da metodologia CAPM no mercado nacional (beta e prêmio de risco), foram utilizadas referências do mercado norte-americano para empresas têxteis. As demais variáveis do modelo foram provenientes do mercado brasileiro. Com isso foi calculado o custo do capital próprio ajustado ao risco de mercado brasileiro. Para o cálculo do capital de terceiros, foi considerado o custo médio ponderado dos empréstimos de longo prazo deduzidos os benficios fiscais. A terceira fase consistiu na apuração do lucro econômico gerado por cada uma das UNs.

No Quadro 1, apresenta-se um modelo esquemático que evidencia os principais elementos dos diferentes conceitos integrados na modelagem proposta.

\begin{tabular}{|c|c|c|c|c|c|}
\hline Operações & UN1 & UN2 & UN3 & $\begin{array}{c}\text { UN- } \\
\text { Corporativa }\end{array}$ & Empresa \\
\hline & $\begin{array}{c}\text { Ativos } \\
\text { Operacionais } \\
\text { Líquidos }\end{array}$ & $\begin{array}{c}\text { Ativos } \\
\text { Operacionais } \\
\text { Líquidos }\end{array}$ & $\begin{array}{c}\text { Ativos } \\
\text { Operacionais } \\
\text { Líquidos }\end{array}$ & $\begin{array}{c}\text { Demais Ativos e } \\
\text { Passivos }\end{array}$ & Ativos e Passivos \\
\hline$=$ & Receita Líquida & Receita Líquida & Receita Líquida & $\begin{array}{c}\text { Receita Líquida } \\
\text { Total }\end{array}$ \\
\hline
\end{tabular}




\begin{tabular}{|c|c|c|c|c|c|}
\hline - & $\begin{array}{c}\text { Custos e } \\
\text { Despesas } \\
\text { Variáveis } \\
\text { Identificadas }\end{array}$ & $\begin{array}{c}\text { Custos e } \\
\text { Despesas } \\
\text { Variáveis } \\
\text { Identificadas }\end{array}$ & $\begin{array}{c}\text { Custos e } \\
\text { Despesas } \\
\text { Variáveis } \\
\text { Identificadas }\end{array}$ & & $\begin{array}{c}\text { Custos Totais e } \\
\text { Despesas Totais } \\
\text { Variáveis } \\
\text { Identificadas }\end{array}$ \\
\hline$=$ & Margem Bruta & Margem Bruta & Margem Bruta & & $\begin{array}{c}\text { Margem Bruta } \\
\text { Total }\end{array}$ \\
\hline- & $\begin{array}{l}\text { Custos de } \\
\text { Despesas Fixas } \\
\text { Identificadas }\end{array}$ & $\begin{array}{l}\text { Custos de } \\
\text { Despesas Fixas } \\
\text { Identificadas }\end{array}$ & $\begin{array}{l}\text { Custos de } \\
\text { Despesas Fixas } \\
\text { Identificadas }\end{array}$ & & $\begin{array}{c}\text { Custos de } \\
\text { Despesas Fixas } \\
\text { Identificadas } \\
\text { Total }\end{array}$ \\
\hline$=$ & $\begin{array}{l}\text { Contribuição } \\
\text { Operacional }\end{array}$ & $\begin{array}{l}\text { Contribuição } \\
\text { Operacional }\end{array}$ & $\begin{array}{l}\text { Contribuição } \\
\text { Operacional }\end{array}$ & & $\begin{array}{c}\text { Contribuição } \\
\text { Operacional Total }\end{array}$ \\
\hline+ & & & & $\begin{array}{l}\text { Resultados Não } \\
\text { Operacionais }\end{array}$ & \\
\hline+ & & & & $\begin{array}{l}\text { Resultados } \\
\text { Financeiros }\end{array}$ & \\
\hline$=$ & $\begin{array}{l}\text { Resultado } \\
\text { Corporativo }\end{array}$ & $\begin{array}{l}\text { Resultado } \\
\text { Corporativo }\end{array}$ & $\begin{array}{l}\text { Resultado } \\
\text { Corporativo }\end{array}$ & $\begin{array}{l}\text { Resultado } \\
\text { Corporativo }\end{array}$ & $\begin{array}{c}\text { Resultado } \\
\text { Corporativo Total }\end{array}$ \\
\hline - & $\begin{array}{c}\text { Custo de } \\
\text { Remuneração do } \\
\text { Capital }\end{array}$ & $\begin{array}{c}\text { Custo de } \\
\text { Remuneração do } \\
\text { Capital }\end{array}$ & $\begin{array}{c}\text { Custo de } \\
\text { Remuneração do } \\
\text { Capital }\end{array}$ & $\begin{array}{c}\text { Custo de } \\
\text { Remuneração } \\
\text { do Capital }\end{array}$ & $\begin{array}{c}\text { Custo de } \\
\text { Remuneração do } \\
\text { Capital Total }\end{array}$ \\
\hline$=$ & $\begin{array}{l}\text { Contribuição } \\
\text { Econômica }\end{array}$ & $\begin{array}{l}\text { Contribuição } \\
\text { Econômica }\end{array}$ & $\begin{array}{l}\text { Contribuição } \\
\text { Econômica }\end{array}$ & $\begin{array}{l}\text { Contribuição } \\
\text { Econômica }\end{array}$ & $\begin{array}{c}\text { Contribuição } \\
\text { Econômica Total }\end{array}$ \\
\hline$=$ & & & & & Lucro Econômico \\
\hline
\end{tabular}

Quadro 1: Modelo esquemático usado para apuração do lucro econômico na indústria têxtil

À medida que os relatórios começaram a ser usados, foi possível constatar problemas de inconsistências das informações obtidas, as quais estavam associadas a erros de diversas naturezas, principalmente, a como elas foram construídas e como estavam disponíveis nas bases de dados, a saber: erros de classificação de contas contábeis, erros de alocação nos centros de responsabilidade, erros de lançamento, etc. Apesar de tal reconhecimento do risco de uso dessas informações, a utilização da informação foi considerada válida. A princípio como informação de tendência, e período a período como medida efetiva de desempenho.

Diversas ações foram tomadas com o intuito de promover a melhoria do processo de contabilização. A primeira ação visou à adequação do plano de contas e dos centros de responsabilidade. Também foram revistas as estruturas dos lançamentos contábeis à luz dos fenômenos que seriam analisados, ou seja, apurar a geração de lucro econômico das unidades de negócio e da organização como um todo. Para tanto, buscou-se implementar 
as recomendações do Comitê de Pronunciamentos Contábeis (CPC), sobretudo aquelas que geravam impactos sobre os ativos operacionais.

Foram também identificados problemas na forma pela qual o ERP (Enterprise Resource Planning) foi implantado originalmente e que impactavam na apuração das informações contábeis/financeiras, dessa forma optou-se por realizar uma reimplementação total desse software, o que ocorreu e possibilitou, além da melhoria da qualidade da informação, uma maximização da utilização dos recursos existentes, e com isso a melhoria do quadro profissional utilizado para a produção da informação e do processo de gestão como um todo.

Pode-se afirmar que a modelagem descrita no Quadro 1 contribuiu com a racionalidade no uso das informações que eram produzidas e isso motivou o Presidente, os gestores das UNs e o controller a usá-las cada vez mais. Como forma de dar maior significado para os resultados identificados com a modelagem de GBV proposta, foi introduzido o rito mensal para avaliação do desempenho gerado pelas Uns, do qual participam o Presidente, diretores, gestores das UNs e o controller. Nele é analisado o resultado obtido sob a ótica da geração de lucro econômico da corporação e da contribuição econômica gerada por cada uma das UNs. São propostas ações estratégicas e operacionais que têm como objetivo contribuir com a melhoria do resultado.

As principais decisões analisadas nas reuniões mensais de Gestão Baseada em Valor versavam sobre aquelas que cada unidade deveria tomar com base nos principais direcionadores de valor de seus negócios, a saber: os níveis de estoques, os recebíveis, o investimento em máquinas e instalações. Na indústria têxtil, esses direcionadores são extremamente dinâmicos. Os estoques são altamente impactados pelas decisões de lançamentos de coleções, pela ampliação do mix de produtos, pela decisão de importação. De outro lado, os recebíveis são altamente influenciados pela concorrência que atua fortemente no sentido de ampliar vendas como decorrência do aumento dos prazos de pagamento. Por fim, a produtividade é altamente impactada pela utilização de tecnologias que ofereçam melhor desempenho. Decisões complexas com base em estratégias passaram a ser embasadas na análise dos direcionadores de valor. 
Sintetizando as etapas que se sucederam durante todo o processo de 2012 a 2015, pode-se dizer que ocorreram mudanças simples e complexas. As simples foram mudanças operacionais na contabilidade, como a do plano de contas e a adoção de práticas do CPC. As complexas e difíceis foram as que levaram à reimplantação do ERP e à troca de boa parte da equipe de contabilidade, desde seu diretor até grande parte da equipe, ou seja, mudanças estruturais com redução de quadro e custos decorrente do aumento de automação de processos. Mas as que mais impactaram o desempenho foram aquelas decorrentes da adoção dos conceitos de Gestão Baseada em Valor, decorrente da atenção contínua aos direcionadores que geram valor. Como uma das consequências do processo de mudança decorrente do uso da GBV, observa-se que houve uma melhoria do desempenho, seja pela possibilidade de atingir níveis de geração de lucro econômico nos anos de 2013 a 2015, período em que a economia brasileira foi muito difícil, sobretudo para o setor têxtil, seja pela profissionalização e melhoria dos processos de gestão decorrentes do uso racional das informações oferecidas pela GBV.

Como evidências da melhoria do processo de gestão e da geração da informação, pode-se considerar que em 2015 a empresa já recebia pareceres de auditoria externa sobre as demonstrações contábeis financeiras, fato que nunca ocorrera anteriormente em seus mais de 40 anos de história.

No ano de 2015, o lucro econômico da indústria têxtil estudada foi baixo, entretanto o custo de capital para essa organização foi da ordem de $16 \%$ ao ano (devido ao aumento do risco sistêmico da economia brasileira). Isso quer dizer que, mesmo na crise de 2015, essa empresa do segmento da indústria têxtil conseguiu gerar um resultado equivalente a $16 \%$ de seus capitais operacionais líquidos.

\section{CONCLUSÕES E CONSIDERAÇÕES FINAIS}

O objetivo neste trabalho foi apresentar os benefícios gerados pela utilização da GBV como a métrica do lucro econômico para a gestão do desempenho econômico de indústrias de forma geral e mais especificamente no setor têxtil brasileiro. Ao longo deste relato, foram citadas diversas melhorias que contribuíram com a mudança na organização, a saber: 
- no processo de gestão: foram alinhados objetivos e estruturadas políticas sobre gestão de estoques, para realização permanente de investimentos em ativos, e sobre concessão de crédito e prazos para recebíveis. Foram ainda introduzidos ritos de gestão para a tomada de decisão com base na gestão por meio dos direcionadores de valor;

- no sistema de informação: foram melhorados os processos de contabilização e otimizados os processos relacionados à automação dos sistemas de informação. Em suma, foi melhorada a qualidade da geração da informação, o que pode ser confirmado pelo recebimento dos pareceres de auditoria independente aos quais a organização passou a submeter-se;

- melhoria do desempenho: como consequência da melhoria dos processos de gestão embasados no sistema de informações, a organização passou a ter uma melhor gestão do desempenho, o que justifica o resultado no período de 2013 a 2015.

Entende-se que os benefícios alcançados pela indústria têxtil estudada são acessíveis para outras indústrias, sejam ou não do mesmo segmento, e que essa metodologia pode ser replicada por outras organizações.

Sugere-se que esse modelo de GBV seja adotado por empresas de outros segmentos (outras indústrias, varejo, serviços financeiros, etc.) e que novos relatos sejam apresentados a fim de proporcionar mais objetividade no processo de generalização do método e alcance dos benefícios.

\section{REFERÊNCIAS}

Assaf, A. (1999). A contabilidade e a gestão baseada no valor. Revista de Contabilidade do CRC-SP, 9, 8-17.

Assaf Neto, A., Araújo, A. M. P., \& Fregonesi, M. S. F. A. (2006). Gestão baseada em valor aplicada ao terceiro setor. Revista de Contabilidade e Finanças, edição comemorativa, 105-118. Recuperado em 7 de julho, 2016, de http://www.revistas.usp.br/rcf/article/view/34199. 
Biancolino, C. A., Kniess, C. T., Maccari, E. A., \& Rabechini Jr., R. (2012). Protocolo para elaboração de relatos de produção técnica. Revista Gestão e Projetos, 3(2), 294-307.

Bonacim, C. A. G., \& Araújo, A. M. P. (2009). Valor econômico agregado por hospitais universitários públicos. Revista de Administração de Empresas $R A E$, 40(4), 419-433. Recuperado em 7 de julho, 2016, de http://200.144.183.88/handle/BDPI/6159.

Cabello, O; Parisi, C; Oliveira, A. B. S. (2007). Análise das práticas de gestão baseada em valor nas empresas inseridas nos níveis diferenciados de governança corporativa e novo mercado da Bovespa. Anais do Congresso USP de Controladoria e Contabilidade, 7, São Paulo, SP, Brasil.

Castro Junior, F. H, \& Yoshinaga, C. E. (2011). Gestão baseada em valor. In C. Parisi, \& E. Megliorini, Contabilidade gerencial (pp. 239-258). São Paulo: Atlas.

Cunha, D. R., \& Frezatti, F. (2004). Gestão baseada em valor: uma pesquisa no setor hoteleiro do Rio Grande do Norte. Revista Eletrônica de Administração - READ, edição 40, 10(4). Recuperado em 7 de julho, 2016, de http://www.seer.ufrgs.br/read/article/view/41772/0

Dória, R. J., Camargo Filho, E. M., \& Bosquetti, M. A. (2005). Estudo de caso: a liderança participativa na construção do mapa estratégico da COPEL. In: A. R. Coutinho, \& D. Kallás, Gestão da estratégia: experiências e lições de empresas brasileiras (pp. 45-55). Rio de Janeiro: Elsevier.

Ehrbar, A. (1999). EVA valor econômico agregado: a verdadeira chave para a criação de riqueza. Rio de Janeiro: Qualitymark.

Guimarães Jr., F. R. (2009). Gestão baseada em valor através de direcionadores de valor. Anais do Congresso Brasileiro de Custos, 16, Fortaleza, CE, Brasil.

Max, R., \& Soares, J. P. R. F. (2008). A influência da orientação à geração de valor ao acionista nas práticas de gestão de pessoas no ambiente da produção. Gestão da Produção, 15(2), 215-230. Recuperado em 7 de julho, 2016, de http://www.scielo.br/pdf/gp/v15n2/a02v15n2

Parisi, C. (2011). Planejamento e Controle. In C. Parisi, \& E. Megliorini, Contabilidade gerencial (pp. 99-124). São Paulo: Atlas.

Trip, D. (2005). Pesquisa-ação: uma introdução metodológica. Educação e Pesquisa, 1(3), 443-466. 
